\title{
Business diversification and multifaceted markets
}

\author{
Koki Arai $^{1}$ (1) $\cdot$ Shuya Hayashi
}

Received: 19 October 2020 / Accepted: 22 April 2021 / Published online: 11 May 2021

(c) The Author(s) 2021

\begin{abstract}
In this paper, we examine multiple segments, conventionally analyzed from the perspective of business diversification, from multiple perspectives in a multifaceted market. Specifically, based on segmental financial data, we conduct an empirical analysis of whether increased sales in the transportation business increase the profit margin of the real estate business of a railroad company. The results show that there are two types of sidedness among many businesses. The effects of both positive and negative indirect network effects were found to exist. In addition, verification of the difference-in-differences based on the initiation event of the mutual traffic interconnection demonstrates the indirect network effect in the transportation business to a certain extent, and shows that the effect is not uniform in each business, with some businesses showing strong effects and others showing less visible effects.
\end{abstract}

Keywords Business diversification · Indirect network effect · Japan · Multifaced market

\section{Introduction}

This paper analyzes the multiple segments of private railways from a multimarket perspective, which has often been earlier analyzed only from the perspective of business diversification.

The social background and impetus for the conception of this study are as follows. Recent developments in information and communication technology (ICT) have brought significant changes to both large and traditional industries. Three main issues are involved. First, what it means to dominate a market. Second, how market

Koki Arai

koki.arai@nifty.ne.jp

1 Faculty of Business, Kyoritsu Women's University, 2-2-1 Hitotsubashi, Chiyoda-ku, Tokyo, Japan

2 Graduate School of Law/The Applied Social System Institute of Asia, Nagoya University, Nagoya, Aichi, Japan 
dominance is measured. Third, how should abuse of market dominance and avoidance of competition be dealt with.

Market dominance is the ability to set prices above the competitive level. It also refers to the ability to artificially influence the terms of trade. The factors that determine market dominance in data involve the quality and quantity of information. These are the factors that enhance market control, regardless of whether the firm in question has big data [33].

How to measure market dominance, and especially how to capture the market in the context of ICT developments and new market conditions, is a challenge. It is necessary to consider anti-competitiveness separately in the following cases, taking into account the various data-enabled realities of society. First, it is a contract subject to monopoly regulation. Second, it is the issue of how to consider the existence of large firms that makes it difficult for new entrants to obtain data. Finally, there is the issue of two-sided markets.

The third issue, abuse of market dominance and avoidance of competition, also poses several challenges to data privacy or infrastructure investment; however, various measures are being considered to counter them, including competition law response.

There are various possible responses to these issues of market and economic activity in the context of sophistication of society and advancement of science and technology. The main approach is to analyze markets and economic structures from the demand side. For example, market dominance has been modeled and empirically analyzed based on how firms behave to maximize their profits under the demand curve.

In contrast, the analysis of private sector corporate diversification strategies to date has been based on the supply side of the analysis. For example, Song [29] performs a stochastic frontier analysis using financial data to estimate the multi-product distance function and estimate the efficiency index with respect to private railroad firms' diversification strategies. (The results do not show a clear relationship between the degree of diversification and efficiency.) In addition, Song [30] estimates an inefficiency model along with technical efficiency and finds that the degree of diversification has a negative impact on efficiency, while the development of the real estate business and pure holding company system has an effect on efficiency. As a result, diversification through a systematic and manageable corporate system is suggested as a management implication. Furthermore, Song and Shoji [31] find a small but positive relationship of the diversification index (segmental Herfindahl index) with railway investment with respect to the impact of diversification strategies on investment behavior, indicating that such strategies can be linked to revenue streams.

For diversification strategies in general, capital markets are also discounted in Japan, as confirmed by Hiramoto [15], Tsuchimura et al. [35], and Hanasaki and Matsushita [14]. Widening the investment opportunity gap has been pointed out to be inefficient and Tsuchimura et al. [35].

However, most of these analyses of business diversification have looked at the linkages and efficiencies between businesses on the supply side, and the implications of diversification from the demand side have not been seen. The principles of 
the economics of demand seem to suggest that firms achieve a combination of price and quantity in response to the elasticity of demand in each market. For example, using the Internet, "as the number of people who use such services to provide goods, etc. increases, the benefits to those who receive such goods, etc. are significantly increased, and this increases the number of recipients, which in turn significantly increases the benefits to the providers, which in turn further increases the number of providers" (from Article 2(1)(1) of the Law on Enhancing Transparency and Fairness of Certain Digital Platforms). Regulations for the relationships have been introduced May 27, 2020. It targets indirect network effects between multiple markets, which also requires theoretical and empirical analysis of diversification from the demand side. Therefore, this paper examines the effects of the multifaceted market of private railways, which is not a digital platform, but the presence or absence of indirect network effects has not been tested so far.

New perspectives have been added to the efforts of these operators. For example, Mobility as a service (MaaS) is a service that improves people's mobility and the challenges in providing it have been examined by various operators. For example, Sakai [27] describes MaaS initiatives in the EU and points out the importance of compatibility, interoperability, and continuity. In addition, under this MaaS situation, Hörcher and Graham [16] examines whether subscriptions are an efficient pricing tool and points out that differentiated pricing is effective. However, this has also not been examined in terms of demand-side conditions, e.g., what are the indirect network effects with other service offerings. This paper, therefore, attempts to analyze the demand-side conditions in this regard as well. And although the analysis of airports is where we find an analysis of the multifaceted marketability of demand in transport-related demand, although the analysis of airport-related projects can be found $[5,8]$, and in rail-related projects, we do not find anything other than Johansson et al. [17], who looked at the relationship with employment in general. Therefore, to fill this gap, this study analyzes indirect network effects and multifaceted marketability in demand, with a focus on railroad-related demand.

This paper is organized as follows. Section 2 provides a theoretical examination. In this section, in addition to the precedent analysis from a judicial perspective, an economic theoretical analysis is also carried out. Section 3 provides an empirical analysis. It examines several aspects of the indirect network effect from the demand side using data on Japanese private railways. Section 4 is the conclusion.

\section{Theoretical investigation}

\section{Market dominance}

In response to these problems, market dominance has traditionally used the price cost margin as an indicator of market dominance (Lerner's index), which relates to how much higher a firm is able to set its prices compared to its production costs.

In other words, a firm's profit is $P(Q) Q-C(Q)$, where $P(Q)$ is the price, $Q$ is the quantity, $P(Q)$ is the demand function in the market, and $C(Q)$ is the total cost 
function. $Q$, which maximizes the profit, is as follows, taking the first-order condition (FOC):

$$
P(Q)+P \prime(Q) Q-C^{\prime}(Q)=0
$$

If we transform this equation and let $\varepsilon$ be the price elasticity of demand, we obtain Eq. (2):

$$
\frac{P(Q)-C^{\prime}(Q)}{P(Q)}=\frac{1}{\varepsilon}
$$

This means that the price cost margin (markup ratio) is inversely proportional to the price elasticity of the demand for the good.

The extended Lerner indicator in Weyl [36], which is an extension of this indicator for multi-side platforms is instructive as the following Eq. (3),

$$
\frac{P(Q)^{I}-\left(C^{\prime}(Q)^{I}+\alpha N^{J}-\widetilde{\beta}^{J} N^{J}\right)}{P(Q)}=\frac{1}{\varepsilon^{I}},
$$

where $P(Q)^{I}$ is the price in the Imarket, $C^{\prime}(Q)^{I}$ is the cost in the $I$ market, $N^{J}$ is the number of market participants in the $J$ market, $\beta^{J}$ is the average response of marginal customers in the $J$ market (which represents Spence's distortion), and $\varepsilon^{I}$ is the price elasticity in the $I$ market.

In the debate about multi-sided platforms, it has long been argued that belowcost pricing is not indicative of predatory behavior that abuses market dominance $[10,37]$. This is because it is an internal subsidy to users on one side to reflect the interests of users on the other side, and, therefore, does not result in an overall pricing below costs. Similarly, pricing well above cost need not be considered as an indication of significant market power. This is because if the number of users on one side interacts with users on the other side, users on the other side may be charged a higher price. Therefore, measuring market dominance in multi-sided platforms, including two-sided markets, is an old and unsolved problem in the economic analysis of competition law.

The framework of Weyl [36] provides a simple answer to this, that it is a general Lerner index for multiple sides, which encompasses and integrates the previous Lerner indexes proposed for special models such as Armstrong [3] and Rochet and Tirole [25].

Such an approach is to construct them separately for each side of the market, which requires a measurement of the value of marginal user average interactions as well as costs. While this measurement may be difficult, it should not be as difficult as measuring costs. These measures can be used as a test of market dominance as well as the Lerner index. However, since prices are often close to or below zero, an index that will probably be normalized by something other than price is a more attractive measure.

With respect to this estimate, $P^{I}-C^{I}-c N^{J}+\tilde{b}^{J} N^{J}$ is easy to calculate. In this case, the natural test for predation in one market would be whether this is a negative number. In addition, if an overall measure of market dominance is desired, 
weighting in multiple markets is the natural way to aggregate. In the overall Lerner metric, intuitively, if multi-marketability (multi-sided) accounts for the bulk of profits, then we should expect relatively low prices for a given market power, since platforms tend to subsidize user participation. Thus, even if the return on sales is small, if multifaceted marketability (interactivity) is the main source of profit, then it will show significant market dominance. Profits are negative only if the overall Lerner index is negative.

\section{Regulation}

The regulation of multifaceted markets is controversial. An example is the policy debate over caps on interchange fees to card merchants and net neutrality regulations that could be variously interpreted as fees that Internet service providers (ISPs) charge for websites or impose limits on price discrimination.

Any regulation that aims to mimic the optimal benchmarks of Pigouvian and Ramsey pricing should resolve the distortions of both [12]. Indeed, both pricings should resolve a certain percentage of distortions on both sides of a two-sided market, rather than just on one side, as in net neutrality and exchange fee regulation. The magnitude of these distortions suggests that two factors are important: the magnitude of classical market dominance and the distortion of Spence on the other side of the market.

Thus, the new factor in multi-sided marketability (bi-directional) is that regulators should focus most on lowering prices on the opposite side of the market from the side with greater Spence distortions. Thus, ISP regulators should focus on limiting prices in websites (net neutrality) when there is a surplus (in interactions) among loyal users in profitable websites. However, if the situation is reversed, getting ISPs to lower their prices and install more lines in consumers' homes may become a priority.

Second, implementing the regulation of Ramsey pricing requires detailed knowledge of demand that is not normally available to regulators. For this reason, it may be better to regulate only one side of the market, especially if market dominance is believed to be particularly distorting prices on one side. However, a price cap on one side of the market would lower prices on one side by either increasing the number of participants on that side by the platform operator (which the regulator requires) or reducing the number of participants on the other side (which the regulator also does not require), especially if there is a positive interaction, further, it may create distortions. Thus, according to Sheshinski [28], price regulation tends to reduce quality. Of course, this may be desirable if the benefits of the interaction are negative, especially if Spence's distortions are upward. For example, a price cap on newspaper readers may lead to more advertising, but this may be an efficient counterbalance to market forces against advertisers, especially if average readers dislike advertising more than marginal readers, as in tabloid newspapers.

In the case of positive interaction interests and Spence distortions, Sheshinski's proposal for quantity regulation may be better, since it does not change the price incentives on the other side of the market if price regulation is not particularly 
attractive. Individually, the optimal pricing conditions are on the side where participation is given, and primary conditions are not affected by participation. For example, regulators may require ISPs to make a certain percentage of websites available for their services, rather than prohibiting them from charging for websites. Since a natural way to increase website participation without lowering prices is to increase the number of subscribers, this may encourage the adoption of more Internet users. Of course, in markets subject to volume regulation, care must be taken to enforce regulation to ensure that ISPs do not commit fraud by signing up for the smallest websites. Given the diversity of websites, the practical complexities of implementing such a policy may outweigh the theoretical benefits. Moreover, even at the theoretical level, a more detailed analysis is needed to clarify when participation regulation is truly preferable to price regulation and for whom it is intended, taking into account all indirect effects. Nevertheless, such allocation regulations deserve further consideration, at least in a multifaceted network. Empirical analysis is required to verify the necessity and sufficiency of such regulations. For this reason, in the next section, multifaceted network effects will be examined through empirical analysis to determine their impact.

Finally, the above analysis appears to provide a further rationale for allowing price discrimination in the two-sided market, at least when Spence distortions are positive. This is because price discrimination is usually more detrimental because it leads to higher prices for advertisers and may exacerbate market power.

\section{Empirical analysis}

\section{Previous research}

Several antitrust cases can be found, but I would like to mention three major ones here. The first was the Lorain Journal Co. v. United States [22]. LJ's exclusivity agreement with advertisers was challenged by the US Department of Justice (DOJ) as a monopolizing act. In this case, the media market is the link between advertisers and users, while contracts with advertisers create barriers to entry into the media market, making the two-sided market a source of market dominance. While it is possible for any major purchaser to build barriers to entry through such contracts, in this case, it became important that it be a two-sided market.

The second was the Times Herald Printing Co. v. A.H. Belo Corp [34]. The Dallas Morning News entered into an exclusive trade agreement with a content coseller, specifically serialized comics. In response, the Dallas Times Herald filed a lawsuit claiming that this practice violated antitrust laws, which, however, they lost. Newspapers are a platform for advertisers and readers, and this agreement is with a third-party supplier of quality content. As providing readers with higher quality content than their rivals, this strategy made sense regardless of how the advertising market reacted. In this case, the two-sided market was held not to be a central factor (in determining illegality) in understanding the significance of the exclusive dealing agreement. 
The third was the Ohio v. American Express Co [24]. American Express (Amex), a credit card business, prohibited the practice of encouraging customers to pay US card merchants with other companies' cards, which had lower fees than Amex. The US District Court in Brooklyn held that the "prohibition against inducement (evasion)" clause, which was intended to discourage customers from using other companies' cards, violated the antitrust laws. The New York Court of Appeals for the Second Circuit criticized the court for focusing solely on the merchant's benefit of using Amex for payment and not looking at the perks and benefits that cardholders could obtain, arguing that while merchants may want lower fees, the fees are necessary to keep cardholders happy. As long as the source of Amex's market share was the satisfaction of cardholders, there was no reason to intervene in the current functioning of the payment card industry, the court held. With respect to market determination, the Supreme Court held that a single market should be delineated in a way that encompasses demanders such as merchants and cardholders (holding that twosided transaction platforms jointly supply a single commodity service), and that the anti-customer inducement clause should look not only at merchant fees, but rather at the entire credit card transaction. It had to be seen whether it was restricted or raised costs, and since these were not shown, it was held that it did not violate antitrust laws.

In addition, in the Apple Inc. v. Pepper [2], the court ruled that plaintiff standing was found when Apple used its monopoly position to set and collect unreasonable commissions for what it sells to consumers by setting app prices and setting a high commission of $30 \%$. In terms of the economic analysis of the platform, the decision shows whether to view the two-sided nature of the platform as a single transaction is a case-by-case matter.

The empirical analysis is discussed in the following studies: "The literature on two-sided markets is developing rapidly" [26], the estimation of market power in the two-sided market for newspapers [4], the analysis of vertical restrictions taking into account entry in the magazine market [12], the estimation of market dominance in the game industry with a two-sided market nature [21], estimating the effects of newspaper market mergers that also take into account product characteristics [11], analyzing differentiation under a two-sided market based on the ideological nature of newspapers [13], and examining the effects of local television stations on the pricing behavior of intermediaries under the two-sided market nature of local television stations [6]. Other analyses have been conducted from a variety of perspectives. In terms of matching models, it has also been summarized that knowing the observable characteristics of partners may not be enough to estimate the parameters sought (Chiappori and Salanié [7]).

With respect to the economic analysis of the two-sided market in Japan, Doi [9] provides a qualitative analysis of the gaming industry, Kawai [19] provides a qualitative analysis of cross-platform strategies, and Kadota [18] provides a qualitative analysis of Amazon's pricing strategy. In terms of quantitative analysis, Sunada and Ohashi [32] estimated the demand functions of the reader and advertiser sides using magazines as the subject matter. He compared models on whether the Japanese magazine market is competitive or cooperative, and found that both readers and advertisers are competitive. Although there was no estimation of market dominance, 
the average margin rate was $9.3 \%$ (median 18.3\%) for readers and $35.0 \%$ (median $34.8 \%$ ) for advertisers, suggesting that the influence of the readers' side was greater than that of the advertisers' side. In addition, Kuroda [20] analyzed content delivery platforms using mobile phone operators as a two-sided market between mobile phone users and content providers. The results show that subsidies are given from subscribers to content providers, and the policy to promote competition is discussed.

\section{Necessity and sufficiency of railway business research}

This study attempts to estimate the market dominance of the two-sided market using segmental financial information in the railroad business. In some respects, the two-sided marketability in the railroad business is similar to that in the magazine and newspaper business, but it is not intuitively clear whether customer growth is directly related to the profitability of the other businesses. This study examines the general view that an increase in customers in the market for transportation services as a way to ensure the footfall of residents along the line leads to growth in other markets, such as the growth of residents' leisure services, the expansion of real estate transactions along the line, and an increase in customers in the retail and other distribution businesses for residents along the line. It considers the potential for indirect network effects outside the market, such as the impact of increased sales from the rail business on market expansion in other businesses (e.g., leisure and services, real estate, distribution, etc.), not only through direct prices, but also through the impact of increased customers. This would appropriately satisfy the need for empirical research to understand indirect network effects beyond the inherent need for rail business research.

This segmental information on the railway business to be studied provides an example of how to understand market dominance in a new industry, including platforms, which is the objective of this paper, whose methodology and results are considered to be a sufficient contribution to digital market research. The segment information under consideration here is disclosed in such a way that it provides appropriate information about the various business activities undertaken by an entity and the operating environment in which the entity operates, so that users of financial statements can understand the entity's past performance and properly evaluate forecasts of future cash flows (Accounting Standards Board of Japan [1]). Business segments are (1) those related to business activities that earn revenue and incur expenses; (2) those for which the entity's chief operating decision-making body makes decisions about the resources to be allocated to the component unit and periodically registers its operating results for the purpose of evaluating its performance, and (3) those for which discrete financial information is available. It is considered applicable to all.

The use of segmental information in this paper is based on the following three points. First, it allows us to analyze business behavior more appropriately by looking directly at the decision-making criteria for business behavior; second, it allows us to look at both the industry of natural monopoly and other business markets for each individual business in terms of the competitive situation in each competing market. 
This is because the data are believed to allow for the identification of the two-sided marketability of the transportation business and other businesses. The third point is as follows: although the Amex case decision was considered to be a joint transaction, it was believed that the two-sided marketability would be more clearly identified between the transportation business and other businesses.

\section{Data and models}

The data for the 11 major railroad companies in the Nikkei NEEDS Financial Quest are as follows: (1) transportation (Transportation revenue: ts, Transportation profit: tp); (2) leisure services revenue: 1s, Leisure Services profit: 1p), (3) real estate (sales of the real estate business: es, profit of the real estate business: ep), and (4) distribution business (sales of the distribution business: rs, profit of the distribution business: rp). These figures are common to all the major railway companies (except Odakyu Electric Railway, which does not have leisure and service operations), and to some of the other companies. In addition, some other companies have indicated that they are in the construction business, but these are not included here.

The transportation business is shared by all the companies and includes the railway business and the bus and taxi businesses, which are the core businesses of the companies under consideration. With the exception of the Odakyu Electric Railway, the Leisure and Service segment includes amusement parks, sightseeing, sports facilities, and hotels. The Real Estate segment is common to all companies, and includes real estate subdivisions and real estate leasing. The distribution business includes department stores and retail store businesses [23].

The descriptive statistics for the data used are shown in Table 1.

First, we check whether the transportation business, which is the core business of each company, is two-sided in relation to the other businesses. As a method to examine the indirect network effect, we confirm that $\beta 4.1$ in the following equation using Eq. (4) is positive and significant, as is the coefficient on the sales of the transportation business.

$$
\begin{aligned}
& \text { Return on sales } \\
& \quad=\text { Related Segment } \\
& +\beta_{4,1} \operatorname{Sales}_{\text {Transportation Business Segment }}\left(+\beta_{4,2} \text { Sales }_{\text {Related Segment }}+\beta_{4,3}\left(\operatorname{Sales}_{\text {Related Segment }}\right)^{2}\right) \\
& + \text { firm fixed effects }+ \text { time fixed effects }+\varepsilon_{4}
\end{aligned}
$$

This is estimated for the leisure and services, real estate, and distribution businesses. The data are from the fiscal year ended March 2010 to the fiscal year ended December 2019.

\section{Estimation results}

The results show that the coefficient of determination, adjusted for degrees of freedom, generally dampens from 0.7 to 0.8 , explaining about $70-80 \%$ of the variation. 


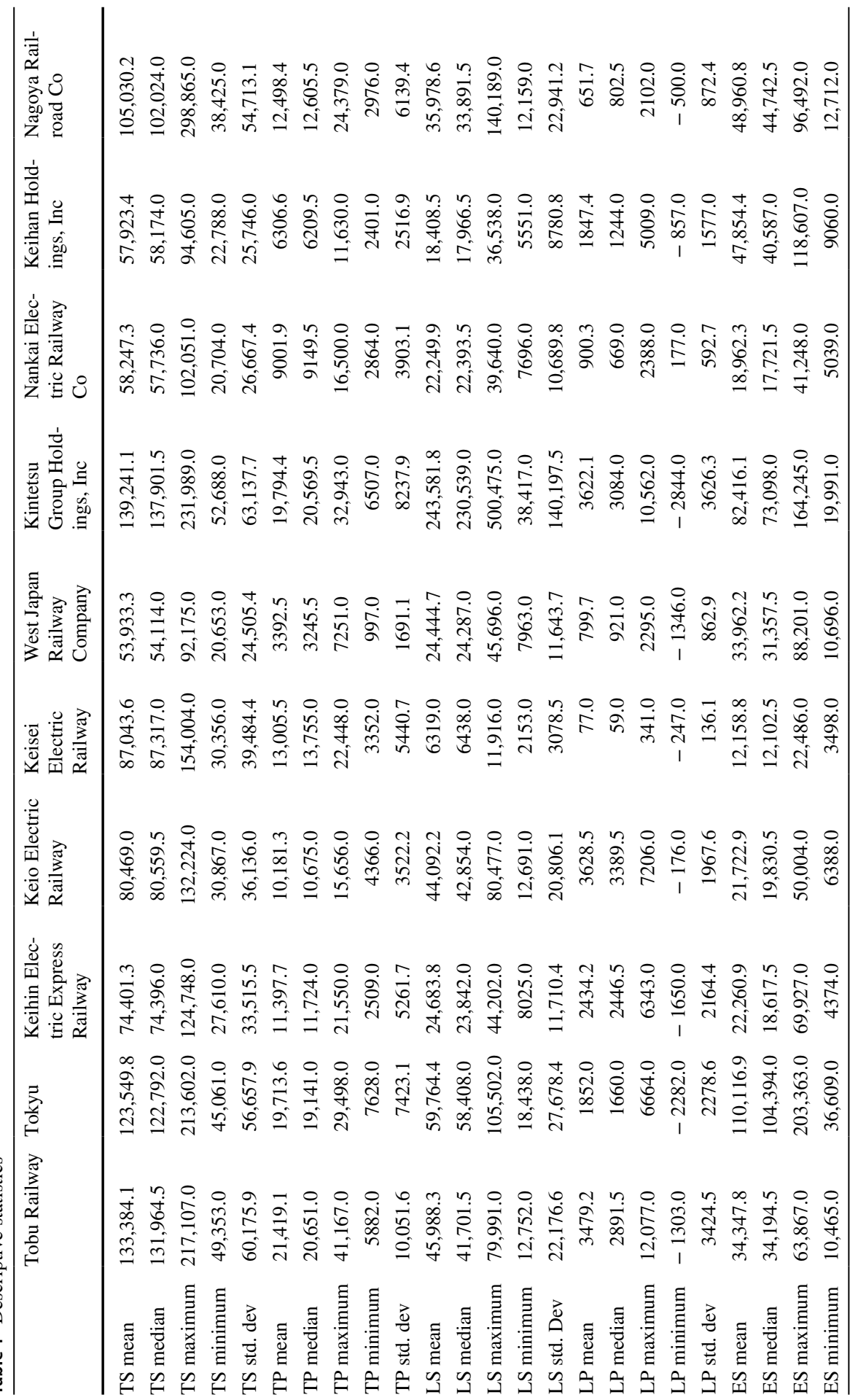




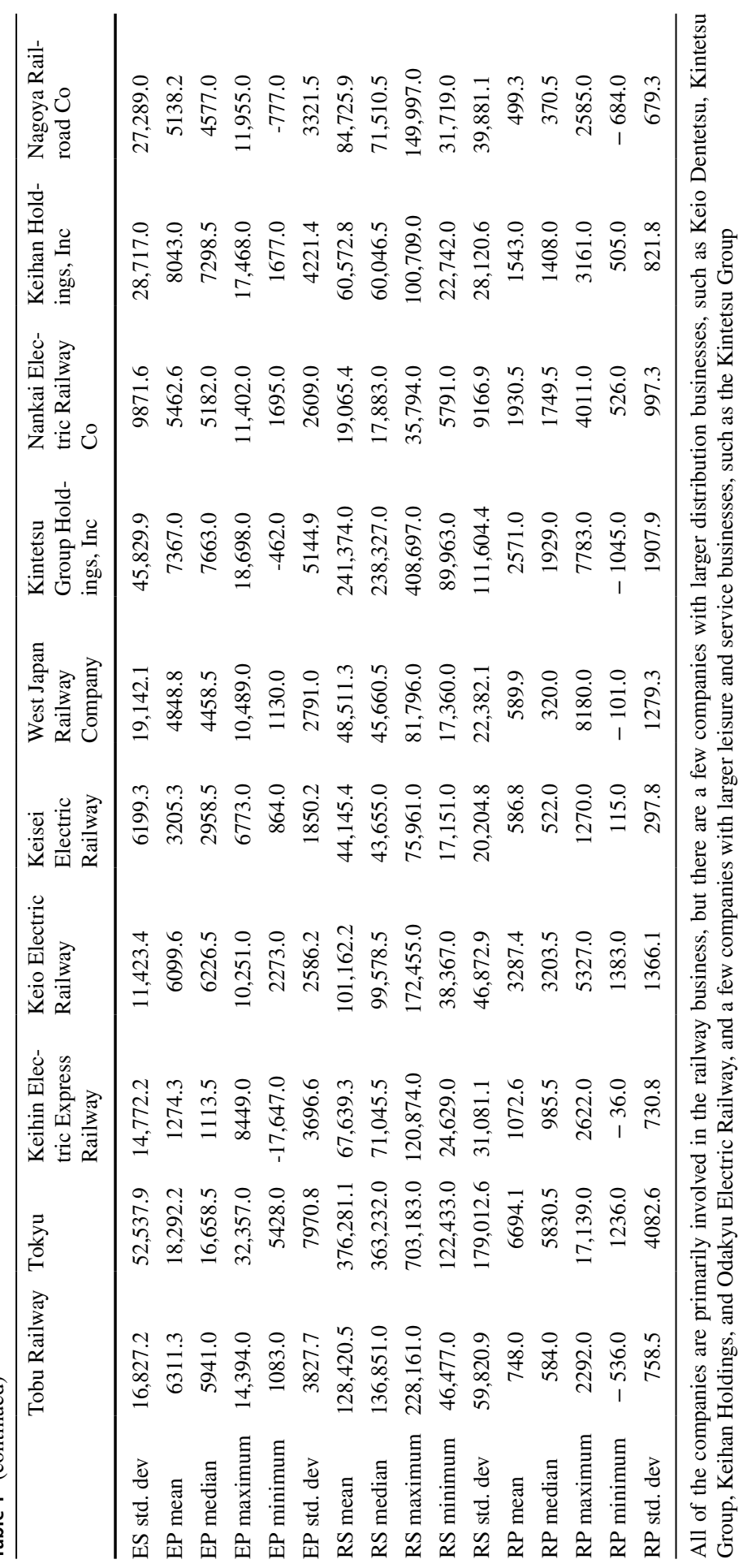


In terms of the relationship between each business and the transportation business, the increase in sales of the transportation business has a positive effect on the leisure and services business (row 2: the values of ts. Positive indirect network effect). We do not find a significant relationship between real estate and distribution businesses. Considering the effect of the size of sales of each business itself and its square effect, the distribution business also has a positive effect. There is a possibility of the reverse causality that success of leisure or real estate division increases profit of transportation division.

The results are shown in Table 2.

Similarly, the relationship between these four businesses is estimated using the following Eq. (5), as shown in Table 3. It looks at the relationship between the increase in sales of each business and the increase in the target's operating margin of sales.

$$
\begin{aligned}
& \text { Return on sales }{ }_{\text {Related Segment }}=\operatorname{Constant}(C)_{\text {Related Segment }} \\
& +\sum \beta_{5,1} \text { Sales }_{\text {Other than Related Segment }}\left(+\beta_{5,2} \operatorname{Sales}_{\text {Related Segment }}\right) \\
& + \text { firm fixed effects }+ \text { time fixed effects } \varepsilon_{5}
\end{aligned}
$$

According to the results, excluding or adding the sales of the business in question does not make a significant difference to the adjusted coefficient of determination, both of which explain between 70 and $80 \%$ of the total variation. As a result of the two-sided nature of the results, the profit margin of the transportation business increases when sales of the real estate business increase, and decreases when sales of the leisure services and distribution businesses increase. The profit margin of the leisure services business increases when sales of the transportation business increase, and the profit margin of the real estate business increases when sales of the leisure services and distribution businesses increase. The profit margin of the real estate business will increase with an increase in sales of the leisure service business. The profit margin of the distribution business will increase when sales of the real estate business increase. Profit margins are about $17 \%$ on average for the real estate business and about $14 \%$ on average for the railroad business, while those of the leisure services and distribution businesses are about $1-2 \%$ each.

In other words, it is possible that the transportation business may subsidize the leisure services and distribution businesses internally (profits in the transportation business would be higher if the leisure services and distribution businesses are a bit smaller), and that the positive effect of the leisure services and distribution businesses on the real estate business may be one of the reasons for this outcome.

Table 4 shows the results of the modified Lerner index of market dominance for the transportation business, often referred to as the so-called natural monopoly industry for each company.

Next, we examine whether a positive indirect network effect on the two-sided market occurs through a difference-in-difference test. Specifically, we consider a disruption in Tobu Railway and Tokyu on March 16, 2013, when the Tobu-Tojo Line started interconnecting with the Tokyu Toyoko Line via the Tokyo Metro Fukutoshin Line during the period under study (see Fig. 1). This event is added 


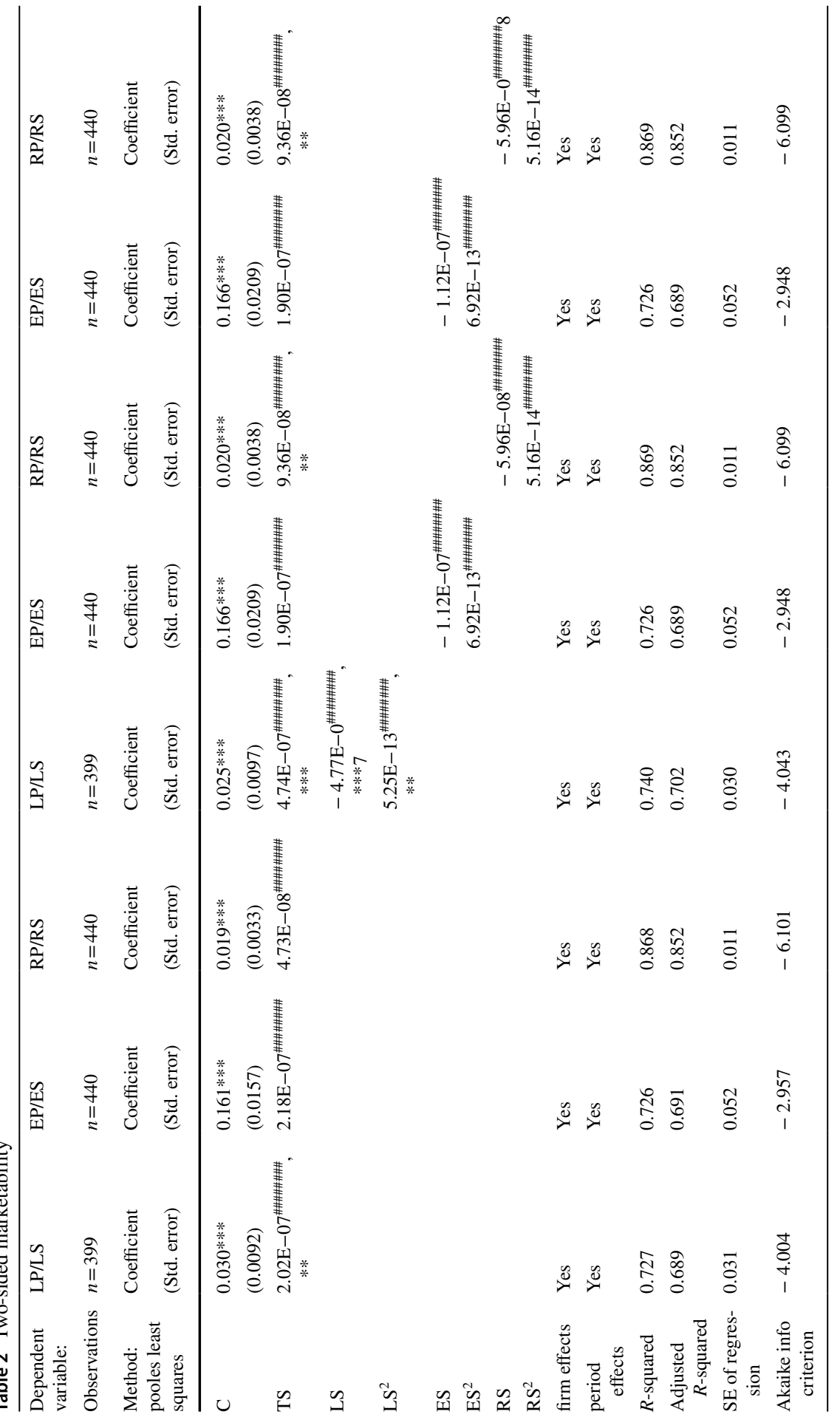




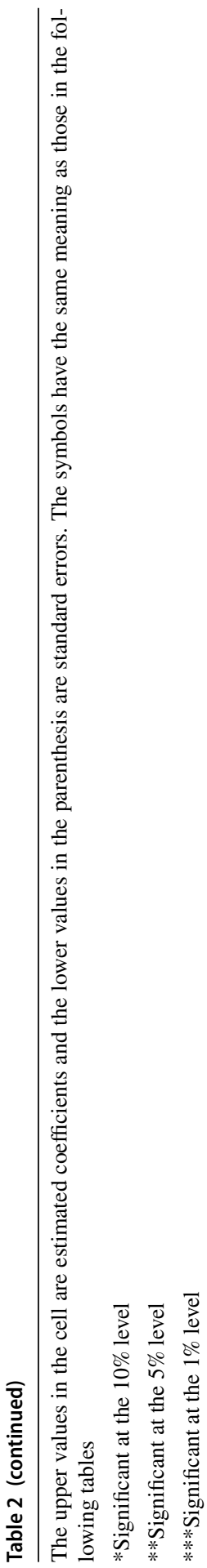

Springer 


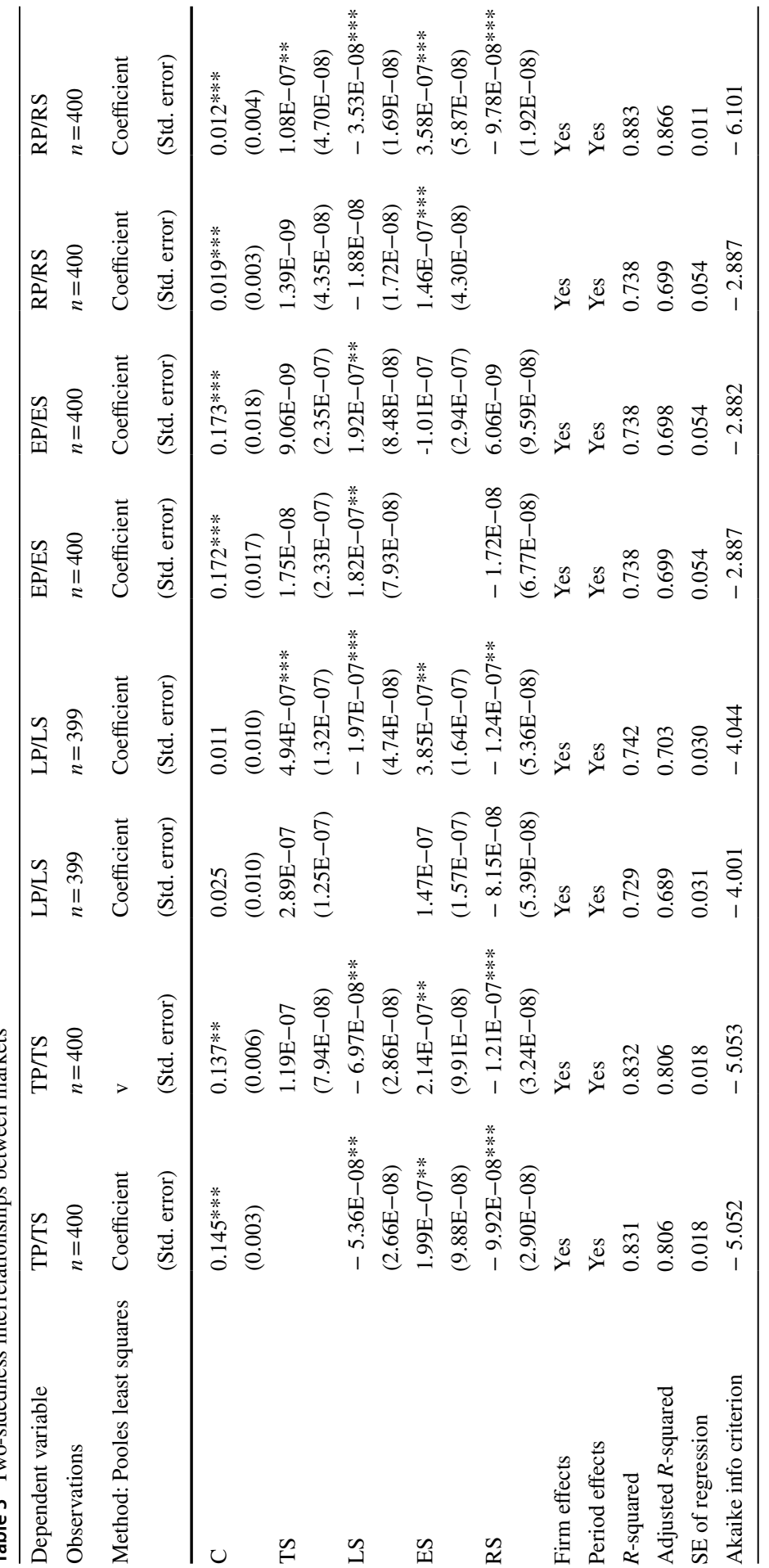


Table 4 Adjusted Lerner Index of the transport business for each company
Company name

Modified

Lerner Index

$(\%)$

Tobu Railway

17.4

Tokyu

18.8

Keihin Electric Express Railway

16.0

Keio Electric Railway

Keisei Electric Railway

West Japan Railway Company

6.4

Kintetsu Group Holdings, Inc

16.7

Nankai Electric Railway Co

15.8

Keihan Holdings, Inc

11.5

Nagoya Railroad Co

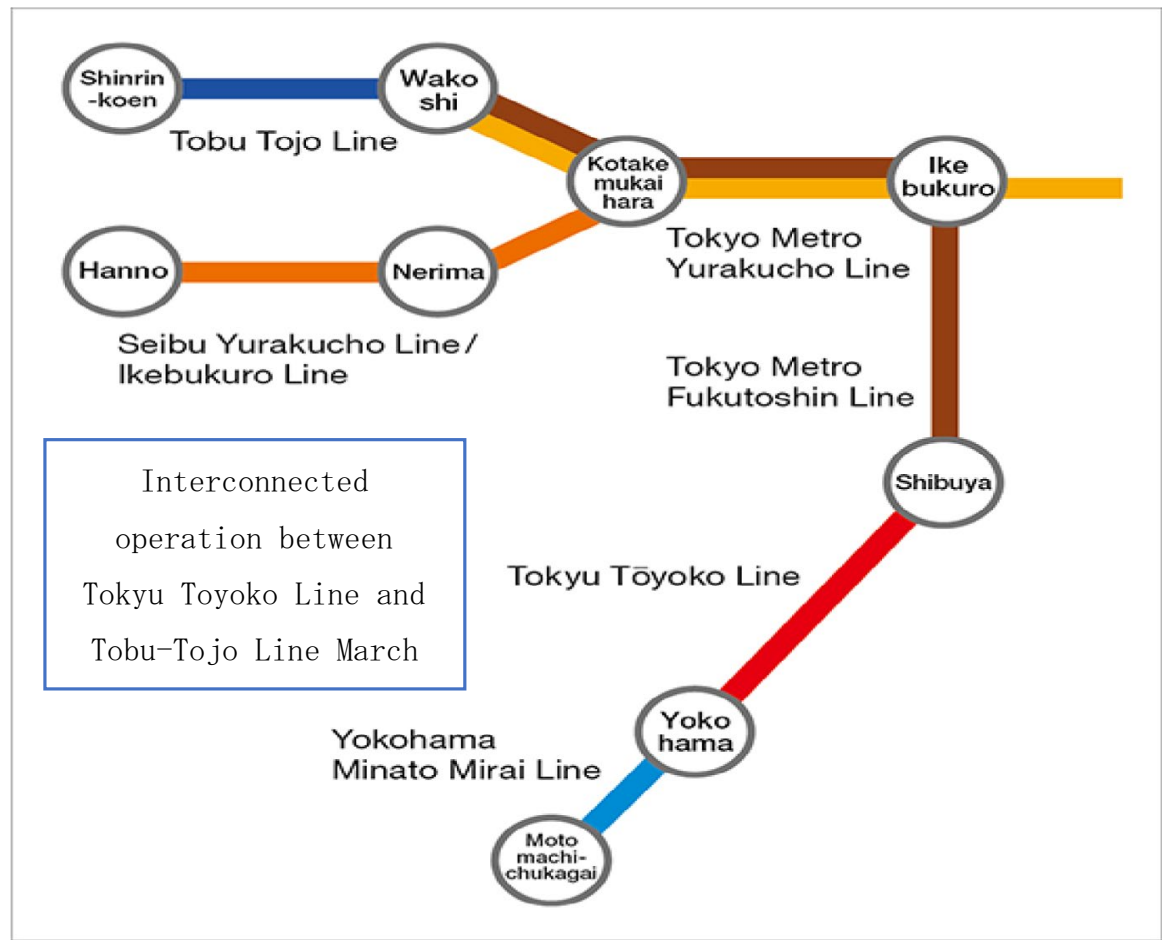

Fig. 1 Tobu-Tokyu interconnection. From the Tokyu website

as a dummy variable (IC) in the case of Tobu Railway and Tokyu (a variable that takes 1 after the start of interconnections and 0 otherwise). We attempt to test the effect of interconnections (i.e., if there is a positive effect, we assume that the 
Table 5 Verification of the two-sidedness difference-in-difference testing

\begin{tabular}{lllll}
\hline Dependent variable & TP/TS & LP/LS & EP/ES & RP/RS \\
Observations & $n=400$ & $n=399$ & $n=400$ & $n=400$ \\
Method: Pooles least squares & Coefficient & Coefficient & Coefficient & Coefficient \\
& $($ Std. error) & $($ Std. error) & (Std. error) & (Std. error) \\
\hline C & $0.139^{* * *}$ & 0.009 & $0.164^{* * *}$ & $0.012^{* * *}$ \\
& $(0.006)$ & $(0.010)$ & $(0.018)$ & $(0.004)$ \\
TS & $1.15 \mathrm{E}-07$ & $5.01 \mathrm{E}-07^{* * *}$ & $3.76 \mathrm{E}-08$ & $1.10 \mathrm{E}-07^{* *}$ \\
& $(7.92 \mathrm{E}-08)$ & $(1.31 \mathrm{E}-07)$ & $(2.31 \mathrm{E}-07)$ & $(4.70 \mathrm{E}-08)$ \\
LS & $-7.24 \mathrm{E}-08^{* * *}$ & $-1.92 \mathrm{E}-07^{* * *}$ & $2.10 \mathrm{E}-07^{* *}$ & $-3.42 \mathrm{E}-08^{* *}$ \\
& $(2.86 \mathrm{E}-08)$ & $(4.73 \mathrm{E}-08)$ & $(8.33 \mathrm{E}-08)$ & $(1.70 \mathrm{E}-08)$ \\
ES & $1.94 \mathrm{E}-07^{*}$ & $4.20 \mathrm{E}-07^{* *}$ & $3.44 \mathrm{E}-08$ & $3.66 \mathrm{E}-07^{* *}$ \\
& $(9.96 \mathrm{E}-08)$ & $(1.65 \mathrm{E}-07)$ & $(2.90 \mathrm{E}-07)$ & $(5.91 \mathrm{E}-08)$ \\
RS & $-1.11 \mathrm{E}-07^{* * *}$ & $-1.41 \mathrm{E}-07^{* *}$ & $-5.94 \mathrm{E}-08$ & $-1.02 \mathrm{E}-07^{* * *}$ \\
& $(3.28 \mathrm{E}-08)$ & $(5.43 \mathrm{E}-08)$ & $(9.56 \mathrm{E}-08)$ & $(1.95 \mathrm{E}-08)$ \\
Interconnect & $-0.008^{*}$ & $0.014 *$ & $0.055^{* * *}$ & 0.003 \\
& $(0.005)$ & $(0.008)$ & $(0.014)$ & $(0.003)$ \\
Firm effects & Yes & Yes & Yes & Yes \\
Period effects & Yes & Yes & Yes & Yes \\
$R$-squared & 0.833 & 0.744 & 0.748 & 0.884 \\
Adjusted $R$-squared & 0.807 & 0.705 & 0.710 & 0.866 \\
SE of regression & 0.018 & 0.030 & 0.053 & 0.011 \\
Akaike info criterion & -5.056 & -4.048 & -2.919 & -6.100 \\
\hline & & & &
\end{tabular}

expansion of transit passengers has some kind of an indirect network effect) using the coefficient in this IC term. The estimated equation is Eq. (5) plus the IC term.

The results are shown in Table 5.

According to the results, the results are interpreted as explaining 70-80\% of the adjusted determination coefficients, which have a certain explanatory power. The noteworthy effect of cross-routing was strongly and significantly positive, especially in the real estate business. The transportation business had a weak and significantly negative effect, while the leisure service business had a weak and significantly positive effect. The results indicate that the transportation business itself was not positively affected by cross-transportation, but the real estate business and the leisure service business, which have two-sided market characteristics, were positively affected by cross-transportation.

\section{Empirical analysis results}

This section of the empirical analysis examines the two-sided marketability between segments in the rail business and confirms the potential for internal subsidies of the transportation business to the leisure and service business and the distribution 
business as well as the fact that the real estate business has a particularly strong indirect network effect with the transportation business, not only in the panel analysis, but also in the difference-in-differences analysis. From the point of view of preventing the abuse of market dominance, these results should be utilized in the future as background information that needs to be examined in more detail when some questionable activities occur.

\section{Conclusion}

Competition laws and policies aim to ensure a vigorous competitive process in the marketplace to protect domestic customers regardless of the nationality of the parties involved. In the context of the growing oligopoly of digital platforms, the Japanese government has established data portability that allows for migration from a particular platform at any time, thus creating an environment in which new platform-based businesses can emerge in rapid succession for vigorous competition to take place.

In addition, further discussions on economic empirical analysis are necessary for the following considerations. It is necessary to analyze the market from the demand side, not just the analysis of business development on the supply side. In this study, as a concrete example of the verification, we conducted an empirical analysis of two-sided marketability based on segmental financial data, including the aspect on whether the increase in sales of the transportation business raises the profit margin of the real estate business for railway companies. The results show that there is a two-sidedness among many businesses. The effects were found to be both positive indirect network effects and negative ones (such as too much advertising leading to fewer subscribers, so to speak). By examining the differences based on the startup events of the crossover, we find that the indirect network effect in the transportation business is demonstrated to a certain extent, and that its manifestation is not uniform across businesses, with some businesses showing strong effects and others showing less visible effects. Although we also estimate market dominance using an actual modified Lerner index, we do not estimate Spence's distortions in this study, and we may need to further improve the accuracy of our estimates when discussing actual policy.

There are three management implications of this study. First, in business diversification, it is easy to be blinded by supply side efficiency, including the economics of scope. However, there is a need for strategic policy formulation from the demand side, such as the presence or absence of indirect network effects that go beyond simply considering prices and volumes in response to differences in the elasticity of demand in different markets. Second, indirect network effects may also, however, have a negative effect, and, therefore, careful policy formulation based on empirical analysis, such as social experiments and data processing, is needed in the actual development of the project, even from a tactical perspective. Third, the analysis of the multifaceted market among the segments of private railways, in particular, confirms the results of previous research on business diversification (e.g., the development of the real estate business has a positive impact on efficiency), since the transportation business has an indirect network effect on the leisure and service business 
and the distribution business. Further elaboration may be needed on how the decline in profit margins may be due to segment characteristics that are separate from business strategy.

The policy implication of this study is that the manifestations of indirect network effects are not uniform for operators operating in multifaceted markets, and it is important to look at ensuring appropriate competition on a case-by-case basis. One of the limitations and challenges of this study is that it is a case study of a large private railway company. However, the methodology in this paper, which analyzes companies and industries that have traditionally been analyzed from the perspective of business diversification from a demand perspective, has great potential for application beyond case studies. In this sense, we need to expand the scope of our analysis to include digital platforms, which have become a challenge today, and promote further empirical research.

Acknowledgements We are grateful to Yoshitaka Tsuruta and Shuhei Yamashita for their assistance in the preparation of this article. An earlier version of this paper was presented at the 2020 Japan Economic Policy Conference, and we received valuable comments from Iko Nago, Keiko Ishihara, and Kyosuke Kasuga. We would also like to thank them for their valuable comments. Part of this work was supported by a Grant-in-Aid for Scientific Research, Japan Society for the Promotion of Science (Grant numbers 19K02018 and 19K01610). Part of this work was supported by the Telecommunications Advancement Foundation (Grant number Net Neutrality and Antitrust). We would like to thank the referee for pointing out that we improved our paper.

Open Access This article is licensed under a Creative Commons Attribution 4.0 International License, which permits use, sharing, adaptation, distribution and reproduction in any medium or format, as long as you give appropriate credit to the original author(s) and the source, provide a link to the Creative Commons licence, and indicate if changes were made. The images or other third party material in this article are included in the article's Creative Commons licence, unless indicated otherwise in a credit line to the material. If material is not included in the article's Creative Commons licence and your intended use is not permitted by statutory regulation or exceeds the permitted use, you will need to obtain permission directly from the copyright holder. To view a copy of this licence, visit http://creativecommons.org/licen ses/by/4.0/.

\section{References}

1. Accounting Standards Board of Japan. (2010). Corporate Accounting Standard No. 17. The Accounting Standard for Disclosures about Segments of an Enterprise and Related Information, and Corporate Accounting Standard Implementation Guidance No. 20, the Guidance on Accounting Standard for Disclosures about Segments of an Enterprise and Related Information. https://www. asb.or.jp/jp/accounting_standards/accounting_standards/y2008/2008-0321.html. Accessed 4 May 2021

2. Apple Inc. v. Pepper. (2019). 139 S. Ct. 1514; 203 L. Ed. 2 d 802

3. Armstrong, M. (2006). Competition in two-sided markets. RAND Journal of Economics, 37(3), 668-691

4. Argentesi, E., \& Filistrucchi, L. (2007). Estimating market power in a two-sided market: the case of newspapers. Journal of Applied Economics, 22(7), 1247-1266

5. Bracaglia, V., Alfonso, T. D., \& Nastasi, A. (2014). Competition between multiproduct airports. Economics of Transportation, 3(4), 270-281

6. Boik, A. (2016). Intermediaries in two-sided markets: an empirical analysis of the US cable television industry. American Economic Journal Microeconomics, 8(1), 256-282

7. Chiappori, P.-A., \& Salanié, B. (2016). The econometrics of matching models. Journal of Economic Literature, 54(3), 832-861 
8. Czerny, A. I. (2013). Public versus private airport behavior when concession revenues exist. Economics of Transportation, 2(1), 38-46

9. Doi, N. (2017). Business models and competition in a two-sided market: A country examples of the gaming industry. Journal of Economics, 71(3), 43-58 In Japanese.

10. Evans, D. S. (2003). Some empirical aspects of multi-sided platform industries. Review of Network Economics, 2(3), 191-209

11. Fan, Y. (2013). Ownership consolidation and product characteristics: a study of the US daily newspaper market. American Economic Review, 103(5), 1598-1628

12. Ferrari, S., \& Verboven, F. (2012). Vertical control of a distribution network-an empirical analysis of magazines. RAND Journal of Economics, 43(1), 26-50

13. Gentzkow, M., Shapiro, J. M., \& Sinkinson, M. (2014). Competition and ideological diversity: Historical evidence from US newspapers. American Economic Review, 104(10), 3073-3114

14. Hanasaki, M., \& Matsushita, K. (2014). Corporate governance and diversified behavior: An empirical analysis using Japanese corporate data. Journal of Economic Business Research, 34(5), 1-74 In Japanese.

15. Hiramoto, T. (2002). Business diversification and corporate value. Gendai Finance, 12, 31-55 In Japanese.

16. Hörcher, D., \& Graham, D. J. (2020). MaaS economics: Should we fight car ownership with subscriptions to alternative modes? Economics of Transportation, 22, 100167. https://doi.org/10.1016/j. ecotra.2020.100167

17. Johansson E, Camporeale R, Palmqvist C-W (2020) Railway network design and regional labour markets in Sweden. Research in Transportation Economics 20: 121. https://doi.org/10.1016/j.retrec. 2020.100921. Accessed 4 May 2021

18. Kadota, Y. (2019). Pricing strategies for platforms in the two-way market and cost sharing: A case study of Amazon's online shopping. Journal of Communications, 66(4), 23-50 In Japanese.

19. Kawai, T. (2019). A tentative framework of dynamic platform strategy-for the era of GAFA and 5G. Journal of Strategic Management Studies, 11(1), 19-36

20. Kuroda, T. (2010). An analysis of the price structure of mobile phone content delivery platforms using a two-sided market model. Journal of Tokyo Keizai University, 267, 171-189 In Japanese.

21. Lee, R. S. (2013). Vertical integration and exclusivity in platform and two-sided markets. American Economic Review, 103(7), 2960-3000

22. Lorain Journal Co. v. United States. (1951). 342 U.S. 143

23. Moriya, H. (2002). The 15 largest private railway companies and their profit and loss structures: Trends by consolidated and unconsolidated companies and business segment. Journal of Institutional Research Economic Culture, 7, 79-105 In Japanese.

24. Ohio v. American Express Co. (2018). 138 S. Ct. 2274; 201 L. Ed. 2d 678

25. Rochet, J.-C., \& Tirole, J. (2006). Two-sided markets: A progress report. RAND Journal of Economics, 37(3), 645-667

26. Rysman, M. (2009). The economics of two-sided markets. Journal of Economic Perspectives, 23(3), 125-143

27. Sakai, K. (2019). (2019) MaaS trends and policy-level initiatives in the EU. IATSS Research, 43(4), 207-209

28. Sheshinski, E. (1976). Price, quality and quantity regulation in monopoly situations. Economica, 43(17), 127-137

29. Song, J. (2015). Considerations on the impact and efficiency of diversification strategies in Japanese private railway companies. Journal of Transportation Studies, 58, 49-56 In Japanese.

30. Song, J. (2017). An empirical analysis of diversified business development and efficiency in Japanese private railway enterprises. Journal of Transportation Studies, 60, 31-38 In Japanese.

31. Song, J., \& Shoji, K. (2016). The impact of diversification strategies of major private railways on investment behavior. National Economic Journal, 213(5), 17-31 In Japanese.

32. Sunada, M., \& Ohashi, H. (2010). Economic analysis of the two-sided market. In: CPRC Joint Research Report CR-0210 . https://www.jftc.go.jp/cprc/reports/index_files/cr-0210.pdf. Accessed 4 May 2021 In Japanese.

33. Takagi, S. (2020). Literature survey on the economic impact of digital platforms. International Journal of Economic Policy Studies, 14, 449-464.

34. Times Herald Printing Co. v. A.H. Belo Corp. (1991). 820 S.W.2d 206

35. Tsuchimura, N., Sugiura, Y., Sasaki, T., \& Yonezawa, Y. (2010). Diversification and the role of internal capital markets in Japanese firms. Gendai Finance, 27, 41-57 In Japanese. 
36. Weyl, E. G. (2010). A price theory of multi-sided platforms. American Economic Review, 100(4), $1642-1672$

37. Wright, J. (2004). One-sided logic in two-sided markets. Review of Network Economics, 3(1), 44-64

Publisher's Note Springer Nature remains neutral with regard to jurisdictional claims in published maps and institutional affiliations.

Table 2 Two-sided marketability 